\title{
New results on coupled fixed point theory in metric spaces endowed with a directed graph
}

\section{Cristian Chifu* and Gabriela Petrusel}

"Correspondence:

cristian.chifu@tbs.ubbcluj.ro

Department of Business,

Babeş-Bolyai University

Cluj-Napoca, Horea street, No. 7,

Cluj-Napoca, Romania

\begin{abstract}
The purpose of this paper is to present some existence results for coupled fixed points of contraction type operators in metric spaces endowed with a directed graph. Our results generalize the results obtained by Gnana Bhaskar and Lakshmikantham in (Nonlinear Anal. 65:1379-1393, 2006). As an application, the existence of a continuous solution for a system of Fredholm and Volterra integral equations is obtained.
\end{abstract}

MSC: $47 \mathrm{H} 10 ; 54 \mathrm{H} 25$

Keywords: fixed point; coupled fixed point; metric space; connected graph

\section{Preliminaries}

In fixed point theory, the importance of study of coupled fixed points is due to their applications to a wide variety of problems. Bhaskar and Lakshmikantham [1] gave some existence results for coupled fixed point for a mixed monotone type mapping in a metric space endowed with partial order, using a weak contractivity type of assumption.

The purpose of this paper is to generalize these results using the context of metric spaces endowed with a graph. This new research direction in the theory of fixed points was initiated by Jachymski [2] and Gwóźdź-Lukawska, Jachymski [3]. Other results for singlevalued and multivalued operators in such metric spaces were given by Beg, Butt, Radojevic in [4], Chifu, Petrusel in [5].

Our results also generalize and extend some coupled fixed points theorems in partially ordered complete metric spaces given by Harjani, Sadarangani [6], Nieto, RodríguezLópez [7] and [8], Nieto, Pouso, Rodríguez-López [9], O’Regan, Petruşel [10], Ran, Reurings [11], Gnana Bhaskar, Lakshmikantham [1], and Chifu, Petrusel [12].

Let $(X, d)$ be a metric space and $\Delta$ be the diagonal of $X \times X$. Let $G$ be a directed graph, such that the set $V(G)$ of its vertices coincides with $X$ and $\Delta \subseteq E(G)$, where $E(G)$ is the set of the edges of the graph. Assume also that $G$ has no parallel edges and, thus, one can identify $G$ with the pair $(V(G), E(G))$.

Throughout the paper we shall say that $G$ with the above-mentioned properties satisfies standard conditions.

Let us denote by $G^{-1}$ the graph obtained from $G$ by reversing the direction of edges. Thus,

$$
E\left(G^{-1}\right)=\{(x, y) \in X \times X:(y, x) \in E(G)\} .
$$

○2014 Chifu and Petrusel; licensee Springer. This is an Open Access article distributed under the terms of the Creative Commons Attribution License (http://creativecommons.org/licenses/by/2.0), which permits unrestricted use, distribution, and reproduction in any medium, provided the original work is properly cited. 
Let us consider the function $F: X \times X \rightarrow X$.

Definition 1.1 An element $(x, y) \in X \times X$ is called coupled fixed point of the mapping $F$, if $F(x, y)=x$ and $F(y, x)=y$.

We shall denote by $\mathrm{CFix}(F)$ the set of all coupled fixed points of mapping $F$, i.e.

$$
\operatorname{CFix}(F)=\{(x, y) \in X \times X: F(x, y)=x \text { and } F(y, x)=y\} .
$$

Definition 1.2 We say that $F: X \times X \rightarrow X$ is edge preserving if

$$
\begin{aligned}
& {\left[(x, u) \in E(G),(y, v) \in E\left(G^{-1}\right)\right]} \\
& \quad \Rightarrow \quad\left[(F(x, y), F(u, v)) \in E(G) \text { and }(F(y, x), F(v, u)) \in E\left(G^{-1}\right)\right] .
\end{aligned}
$$

Definition 1.3 The operator $F: X \times X \rightarrow X$ is called G-continuous if for all $(x, y) \in X \times$ $X,\left(x^{*}, y^{*}\right) \in X \times X$ and for any sequence $\left(n_{i}\right)_{i \in \mathbb{N}}$ of positive integers, with $F^{n_{i}}(x, y) \rightarrow x^{*}$, $F^{n_{i}}(y, x) \rightarrow y^{*}$, as $i \rightarrow \infty$, and $\left(F^{n_{i}}(x, y), F^{n_{i}+1}(x, y)\right) \in E(G),\left(F^{n_{i}}(y, x), F^{n_{i}+1}(y, x)\right) \in E\left(G^{-1}\right)$, we have that

$$
\begin{aligned}
& F\left(F^{n_{i}}(x, y), F^{n_{i}}(y, x)\right) \rightarrow F\left(x^{*}, y^{*}\right), \\
& F\left(F^{n_{i}}(y, x), F^{n_{i}}(x, y)\right) \rightarrow F\left(y^{*}, x^{*}\right),
\end{aligned}
$$

Definition 1.4 Let $(X, d)$ be a complete metric space and $G$ be a directed graph. We say that the triple $(X, d, G)$ has the property $\left(A_{1}\right)$, if for any sequence $\left(x_{n}\right)_{n \in \mathbb{N}} \subset X$ with $x_{n} \rightarrow x$, as $n \rightarrow \infty$, and $\left(x_{n}, x_{n+1}\right) \in E(G)$, for $n \in \mathbb{N}$, we have $\left(x_{n}, x\right) \in E(G)$.

Definition 1.5 Let $(X, d)$ be a complete metric space and $G$ be a directed graph. We say that the triple $(X, d, G)$ has the property $\left(A_{2}\right)$, if for any sequence $\left(x_{n}\right)_{n \in \mathbb{N}} \subset X$ with $x_{n} \rightarrow x$, as $n \rightarrow \infty$, and $\left(x_{n}, x_{n+1}\right) \in E\left(G^{-1}\right)$, for $n \in \mathbb{N}$, we have $\left(x_{n}, x\right) \in E\left(G^{-1}\right)$.

\section{Coupled fixed point theorems}

Let $(X, d)$ be a metric space endowed with a directed graph $G$ satisfying the standard conditions.

We consider the set denoted by $(X \times X)^{F}$ and defined as

$$
(X \times X)^{F}=\left\{(x, y) \in X \times X:(x, F(x, y)) \in E(G) \text { and }(y, F(y, x)) \in E\left(G^{-1}\right)\right\} .
$$

Proposition 2.1 If $F: X \times X \rightarrow X$ is edge preserving, then:

(i) $(x, u) \in E(G)$ and $(y, v) \in E\left(G^{-1}\right)$ implies $\left(F^{n}(x, y), F^{n}(u, v)\right) \in E(G)$ and $\left(F^{n}(y, x), F^{n}(v, u)\right) \in E\left(G^{-1}\right)$

(ii) $(x, y) \in(X \times X)^{F}$ implies $\left(F^{n}(x, y), F^{n+1}(x, y)\right) \in E(G)$ and $\left(F^{n}(y, x), F^{n+1}(y, x)\right) \in E\left(G^{-1}\right)$, for all $n \in \mathbb{N}$;

(iii) $(x, y) \in(X \times X)^{F}$ implies $\left(F^{n}(x, y), F^{n}(y, x)\right) \in(X \times X)^{F}$, for all $n \in \mathbb{N}$.

Proof (i) Let $(x, u) \in E(G)$ and $(y, v) \in E\left(G^{-1}\right)$. Because $F$ is edge preserving we have $(F(x, y), F(u, v)) \in E(G)$ and $(F(y, x), F(v, u)) \in E\left(G^{-1}\right)$, which, using the same property, will imply that $\left(F^{2}(x, y), F^{2}(u, v)\right) \in E(G)$ and $\left(F^{2}(y, x), F^{2}(v, u)\right) \in E\left(G^{-1}\right)$. 
By induction we shall obtain $\left(F^{n}(x, y), F^{n}(u, v)\right) \in E(G)$ and $\left(F^{n}(y, x), F^{n}(v, u)\right) \in E\left(G^{-1}\right)$.

(ii) Let $(x, y) \in(X \times X)^{F}:(x, F(x, y)) \in E(G)$ and $(y, F(y, x)) \in E(G)$.

Using (i) we have

$$
\begin{aligned}
& \left(F^{n}(x, y), F^{n+1}(x, y)\right)=\left(F^{n}(x, y), F^{n}(F(x, y), F(y, x))\right) \in E(G) \\
& \left(F^{n}(y, x), F^{n+1}(y, x)\right)=\left(F^{n}(y, x), F^{n}(F(y, x), F(x, y))\right) \in E\left(G^{-1}\right) .
\end{aligned}
$$

(iii) From (ii) we have

$$
\begin{aligned}
& \left(F^{n}(x, y), F\left(F^{n}(x, y), F^{n}(y, x)\right)\right)=\left(F^{n}(x, y), F^{n+1}(x, y)\right) \in E(G) \\
& \left(F^{n}(y, x), F\left(F^{n}(y, x), F^{n}(x, y)\right)\right)=\left(F^{n}(y, x), F^{n+1}(y, x)\right) \in E\left(G^{-1}\right) .
\end{aligned}
$$

This is equivalent to $\left(F^{n}(x, y), F^{n}(y, x)\right) \in(X \times X)^{F}$, for all $n \in \mathbb{N}$.

Definition 2.1 The mapping $F: X \times X \rightarrow X$ is called a $G$-contraction if:

(i) $F$ is edge preserving;

(ii) there exists $k \in[0,1)$ such that

$$
d(F(x, y), F(u, v)) \leq \frac{k}{2}(d(x, u)+d(y, v)), \quad \text { for all }(x, u) \in E(G),(y, v) \in E\left(G^{-1}\right) .
$$

Lemma 2.1 Let $(X, d)$ be a metric space endowed with a directed graph $G$ and let $F: X \times$ $X \rightarrow X$ be a G-contraction with constant $k$. Then

$$
\begin{aligned}
& d\left(F^{n}(x, y), F^{n}(u, v)\right) \leq \frac{k^{n}}{2}(d(x, u)+d(y, v)), \\
& d\left(F^{n}(y, x), F^{n}(v, u)\right) \leq \frac{k^{n}}{2}(d(x, u)+d(y, v)),
\end{aligned}
$$

Proof Let $(x, u),(y, v) \in E(G)$. Because $F$ is edge preserving we have $(F(x, y), F(u, v)) \in E(G)$ and $(F(y, x), F(v, u)) \in E\left(G^{-1}\right)$.

From Proposition 2.1(i), it follows that $\left(F^{n}(x, y), F^{n}(u, v)\right) \in E(G)$ and $\left(F^{n}(y, x), F^{n}(v, u)\right) \in$ $E\left(G^{-1}\right)$.

Since $F$ is a $G$-contraction, we shall obtain

$$
\begin{aligned}
d\left(F^{2}(x, y), F^{2}(u, v)\right) & =d(F(F(x, y), F(y, x)), F(F(u, v), F(v, u))) \\
& \leq \frac{k}{2}(d(F(x, y), F(u, v))+d(F(y, x), F(v, u))) \\
& \leq \frac{k^{2}}{2} d((x, y)+d(u, v))
\end{aligned}
$$

and

$$
\begin{aligned}
d\left(F^{2}(y, x), F^{2}(v, u)\right) & =d(F(F(y, x), F(x, y)), F(F(v, u), F(u, v))) \\
& =d(F(F(v, u), F(u, v)), F(F(y, x), F(x, y))) \\
& \leq \frac{k}{2}(d(F(v, u), F(y, x))+d(F(u, v), F(x, y))) \\
& \leq \frac{k^{2}}{2} d((x, y)+d(u, v)) .
\end{aligned}
$$


Hence, by induction, we have

$$
\begin{aligned}
& d\left(F^{n}(x, y), F^{n}(u, v)\right) \leq \frac{k^{n}}{2}(d(x, u)+d(y, v)), \\
& d\left(F^{n}(y, x), F^{n}(v, u)\right) \leq \frac{k^{n}}{2}(d(x, u)+d(y, v)),
\end{aligned}
$$

Lemma 2.2 Let $(X, d)$ be a metric space endowed with a directed graph $G$ and let $F$ : $X \times X \rightarrow X$ be a G-contraction with constant $k$. Then, given $(x, y) \in(X \times X)^{F}$, there exists $r(x, y) \geq 0$ such that

$$
\begin{aligned}
& d\left(F^{n}(x, y), F^{n+1}(x, y)\right) \leq \frac{k^{n}}{2} r(x, y), \quad \text { for all } n \in \mathbb{N} . \\
& d\left(F^{n}(y, x), F^{n+1}(y, x)\right) \leq \frac{k^{n}}{2} r(x, y),
\end{aligned}
$$

Proof Let $(x, y) \in(X \times X)^{F}:(x, F(x, y)) \in E(G)$ and $(y, F(y, x)) \in E\left(G^{-1}\right)$.

If in Lemma 2.1 we consider $u=F(x, y)$ and $v=F(y, x)$ we shall obtain

$$
d\left(F^{n}(x, y), F^{n}(F(x, y), F(y, x))\right) \leq \frac{k^{n}}{2}(d(x, F(x, y))+d(y, F(y, x))), \quad \text { for all } n \in \mathbb{N}
$$

which is

$$
d\left(F^{n}(x, y), F^{n+1}(x, y)\right) \leq \frac{k^{n}}{2}(d(x, F(x, y))+d(y, F(y, x))), \quad \text { for all } n \in \mathbb{N} .
$$

If we consider $r(x, y):=d(x, F(x, y))+d(y, F(y, x))$, then

$$
d\left(F^{n}(x, y), F^{n+1}(x, y)\right) \leq \frac{k^{n}}{2} r(x, y), \quad \text { for all } n \in \mathbb{N} .
$$

In a similar way we obtain

$$
d\left(F^{n}(y, x), F^{n+1}(y, x)\right) \leq \frac{k^{n}}{2} r(x, y), \quad \text { for all } n \in \mathbb{N} .
$$

Lemma 2.3 Let $(X, d)$ be a complete metric space endowed with a directed graph $G$ and let $F: X \times X \rightarrow X$ be a G-contraction with the constant $k$. Then for each $(x, y) \in(X \times X)^{F}$, there exist $x^{*}(x) \in X$ and $y^{*}(y) \in X$ such that $\left(F^{n}(x, y)\right)_{n \in \mathbb{N}}$ converges to $x^{*}(x)$ and $\left(F^{n}(y, x)\right)_{n \in \mathbb{N}}$ converges to $y^{*}(y)$, as $n \rightarrow \infty$.

Proof Let $(x, y) \in(X \times X)^{F}$. From Lemma 2.2, we have

$$
\begin{aligned}
& d\left(F^{n}(x, y), F^{n+1}(x, y)\right) \leq \frac{k^{n}}{2} r(x, y), \\
& d\left(F^{n}(y, x), F^{n+1}(y, x)\right) \leq \frac{k^{n}}{2} r(x, y),
\end{aligned}
$$

Let $m>n$. We have

$$
\begin{aligned}
d\left(F^{n}(x, y), F^{m}(x, y)\right) & \leq d\left(F^{n}(x, y), F^{n+1}(x, y)\right)+\cdots+d\left(F^{m-1}(x, y), F^{m}(x, y)\right) \\
& \leq \frac{1}{2}\left(k^{n}+\cdots+k^{m-1}\right) r(x, y)
\end{aligned}
$$




$$
\begin{aligned}
& =\frac{k^{n}-k^{m}}{2(1-k)} r(x, y) \\
& <\frac{k^{n}}{2(1-k)} r(x, y) \rightarrow 0, \quad \text { as } n \rightarrow \infty .
\end{aligned}
$$

Similarly we shall obtain

$$
d\left(F^{n}(y, x), F^{m}(y, x)\right)<\frac{k^{n}}{2(1-k)} r(x, y) \rightarrow 0, \quad \text { as } n \rightarrow \infty .
$$

Hence $\left(F^{n}(x, y)\right)_{n \in \mathbb{N}}$ and $\left(F^{n}(y, x)\right)_{n \in \mathbb{N}}$ are Cauchy sequences. Since $(X, d)$ is a complete metric space we shall obtain the result that there exist $x^{*}(x) \in X$ and $y^{*}(y) \in X$ such that $\left(F^{n}(x, y)\right)_{n \in \mathbb{N}}$ converges to $x^{*}(x)$ and $\left(F^{n}(y, x)\right)_{n \in \mathbb{N}}$ converges to $y^{*}(y)$, as $n \rightarrow \infty$.

Now we shall prove the main results of this section.

Theorem 2.1 Let $(X, d)$ be a complete metric space endowed with a directed graph $G$ and let $F: X \times X \rightarrow X$ be a G-contraction with the constant $k$. Suppose that:

(i) $F$ is G-continuous;

or

(ii) The triple $(X, d, G)$ has the properties $\left(A_{1}\right)$ and $\left(A_{2}\right)$.

Under these conditions $\operatorname{CFix}(F) \neq \varnothing$ if and only if $(X \times X)^{F} \neq \varnothing$.

Proof Suppose that $\operatorname{CFix}(F) \neq \varnothing$.

Let $\left(x^{*}, y^{*}\right) \in \mathrm{CFix}(F)$.

We have $\left(x^{*}, F\left(x^{*}, y^{*}\right)\right)=\left(x^{*}, x^{*}\right) \in \Delta \subset E(G)$ and $\left(y^{*}, F\left(y^{*}, x^{*}\right)\right)=\left(y^{*}, y^{*}\right) \in \Delta \subset E\left(G^{-1}\right)$.

Hence $\left(x^{*}, F\left(x^{*}, y^{*}\right)\right) \in E(G)$ and $\left(y^{*}, F\left(y^{*}, x^{*}\right)\right) \in E\left(G^{-1}\right)$ which means that $\left(x^{*}, y^{*}\right) \in(X \times$ $X)^{F}$ and thus $(X \times X)_{F} \neq \varnothing$.

Suppose now that $(X \times X)^{F} \neq \varnothing$. Let $(x, y) \in(X \times X)^{F}:(x, F(x, y)) \in E(G)$ and $(y, F(y, x)) \in$ $E\left(G^{-1}\right)$.

Let $\left(n_{i}\right)_{i \in \mathbb{N}}$ be a sequence of positive integers. From Proposition 2.1(ii), we know that

$$
\begin{aligned}
& \left(F^{n_{i}}(x, y), F^{n_{i}+1}(x, y)\right) \in E(G), \\
& \left(F^{n_{i}}(y, x), F^{n_{i}+1}(y, x)\right) \in E\left(G^{-1}\right) .
\end{aligned}
$$

Moreover, from Lemma 2.3, there exist $x^{*}(x) \in X$ and $y^{*}(y) \in X$ such that

$$
\begin{aligned}
& F^{n_{i}}(x, y) \rightarrow x^{*}(x), \\
& F^{n_{i}}(y, x) \rightarrow y^{*}(y),
\end{aligned}
$$

We shall prove that $F\left(x^{*}, y^{*}\right)=x^{*}$ and $F\left(y^{*}, x^{*}\right)=y^{*}$.

Suppose that we have (i). Since $F$ is $G$-continuous we shall obtain that

$$
\begin{aligned}
& F\left(F^{n_{i}}(x, y), F^{n_{i}}(y, x)\right) \rightarrow F\left(x^{*}, y^{*}\right), \\
& F\left(F^{n_{i}}(y, x), F^{n_{i}}(x, y)\right) \rightarrow F\left(y^{*}, x^{*}\right),
\end{aligned}
$$

Now

$$
d\left(F\left(x^{*}, y^{*}\right), x^{*}\right) \leq d\left(F\left(x^{*}, y^{*}\right), F^{n_{i}+1}(x, y)\right)+d\left(F^{n_{i}+1}(x, y), x^{*}\right)
$$


Using the $G$-continuity of $F$ and the convergence of $\left(F^{n}(x, y)\right)_{n \in \mathbb{N}}$ we obtain $d\left(F\left(x^{*}, y^{*}\right)\right.$, $\left.x^{*}\right)=0$, which means that $F\left(x^{*}, y^{*}\right)=x^{*}$.

In a similar way it can be proved that $F\left(y^{*}, x^{*}\right)=y^{*}$.

Thus $\left(x^{*}, y^{*}\right)$ is a coupled fixed point of the mapping $F$; therefore, $\mathrm{CFix}(F) \neq \varnothing$.

Suppose now that we have (ii). From (2.1) and (2.2), using properties $\left(A_{1}\right)$ and $\left(A_{2}\right)$ of the triple $(X, d, G)$, we shall obtain

$$
\begin{aligned}
& \left(F^{n}(x, y), x^{*}\right) \in E(G), \\
& \left(F^{n}(y, x), y^{*}\right) \in E\left(G^{-1}\right), \\
& d\left(F\left(x^{*}, y^{*}\right), x^{*}\right) \\
& \quad \leq d\left(F^{n+1}(x, y), F\left(x^{*}, y^{*}\right)\right)+d\left(F^{n+1}(x, y), x^{*}\right) \\
& \quad \leq d\left(F\left(F^{n}(x, y), F^{n}(y, x)\right), F\left(x^{*}, y^{*}\right)\right)+d\left(F^{n+1}(x, y), x^{*}\right) \\
& \quad \leq \frac{k}{2}\left(d\left(F^{n}(x, y), x^{*}\right)+d\left(F^{n}(y, x), y^{*}\right)\right)+d\left(F^{n+1}(x, y), x^{*}\right) \rightarrow 0, \quad \text { as } n \rightarrow \infty, \\
& d\left(F\left(y^{*}, x^{*}\right), y^{*}\right) \\
& \quad \leq d\left(F^{n+1}(y, x), F\left(y^{*}, x^{*}\right)\right)+d\left(F^{n+1}(y, x), y^{*}\right) \\
& \quad \leq d\left(F\left(F^{n}(y, x), F^{n}(x, y)\right), F\left(y^{*}, x^{*}\right)\right)+d\left(F^{n+1}(y, x), y^{*}\right) \\
& \quad=d\left(F\left(y^{*}, x^{*}\right), F\left(F^{n}(y, x), F^{n}(x, y)\right)\right)+d\left(F^{n+1}(y, x), y^{*}\right) \\
& \quad \leq \frac{k}{2}\left(d\left(F^{n}(x, y), x^{*}\right)+d\left(F^{n}(y, x), y^{*}\right)\right)+d\left(F^{n+1}(y, x), y^{*}\right) \rightarrow 0, \quad \text { as } n \rightarrow \infty .
\end{aligned}
$$

Hence $d\left(F\left(x^{*}, y^{*}\right), x^{*}\right)=0$ and $d\left(F\left(y^{*}, x^{*}\right), y^{*}\right)=0$, which means that $F\left(x^{*}, y^{*}\right)=x^{*}$ and $F\left(y^{*}, x^{*}\right)=y^{*}$.

Thus $\left(x^{*}, y^{*}\right) \in \operatorname{CFix}(F)$.

Let us suppose now that for every $\left(x_{1}, y_{1}\right),\left(x_{2}, y_{2}\right) \in X \times X$ there exists $\left(z_{1}, z_{2}\right) \in X \times X$ such that

$$
\begin{array}{ll}
\left(x_{1}, z_{1}\right) \in E(G), & \left(y_{1}, z_{2}\right) \in E\left(G^{-1}\right), \\
\left(x_{2}, z_{1}\right) \in E(G), & \left(y_{2}, z_{2}\right) \in E\left(G^{-1}\right) .
\end{array}
$$

Theorem 2.2 Adding condition (2.3) to the hypothesis of Theorem 2.1 we obtain the uniqueness of the coupled fixed point of $F$.

Proof Let us suppose that there exist $\left(x_{1}^{*}, y_{1}^{*}\right),\left(x_{2}^{*}, y_{2}^{*}\right) \in X \times X$ two coupled fixed points of $F$. From (2.3) we find that there exists $\left(z_{1}, z_{2}\right) \in X \times X$ such that

$$
\begin{array}{ll}
\left(x_{1}^{*}, z_{1}\right) \in E(G), & \left(y_{1}^{*}, z_{2}\right) \in E\left(G^{-1}\right), \\
\left(x_{2}^{*}, z_{1}\right) \in E(G), & \left(y_{2}^{*}, z_{2}\right) \in E\left(G^{-1}\right) .
\end{array}
$$


Using Lemma 2.1, we shall have

$$
\begin{aligned}
d\left(x_{1}^{*}, x_{2}^{*}\right) & =d\left(F^{n}\left(x_{1}^{*}, y_{1}^{*}\right), F^{n}\left(x_{2}^{*}, y_{2}^{*}\right)\right) \\
& \leq d\left(F^{n}\left(x_{1}^{*}, y_{1}^{*}\right), F^{n}\left(z_{1}, z_{2}\right)\right)+d\left(F^{n}\left(z_{1}, z_{2}\right), F^{n}\left(x_{2}^{*}, y_{2}^{*}\right)\right) \\
& \leq \frac{k^{n}}{2}\left(d\left(x_{1}^{*}, z_{1}\right)+d\left(y_{1}^{*}, z_{2}\right)+d\left(x_{2}^{*}, z_{1}\right)+d\left(y_{2}^{*}, z_{2}\right)\right) \rightarrow 0, \quad \text { as } n \rightarrow \infty
\end{aligned}
$$

Hence $x_{1}^{*}=x_{2}^{*}$.

In a similar way it can be proved that $y_{1}^{*}=y_{2}^{*}$.

Remark 2.1 It is obvious that if $\left(x_{1}^{*}, x_{2}^{*}\right) \in E(G)$ and $\left(y_{1}^{*}, y_{2}^{*}\right) \in E\left(G^{-1}\right)$, then $x_{1}^{*}=x_{2}^{*}$ and $y_{1}^{*}=y_{2}^{*}$.

Theorem 2.3 Under the conditions of Theorem 2.1, if $\left(x^{*}, y^{*}\right) \in \operatorname{CFix}(F)$ with $\left(x^{*}, y^{*}\right) \in$ $E(G)$, then $x^{*}=y^{*}$.

Proof Since $\left(x^{*}, y^{*}\right) \in E(G),\left(y^{*}, x^{*}\right) \in E\left(G^{-1}\right)$, from the $G$-contraction condition we have

$$
d\left(x^{*}, y^{*}\right)=d\left(F\left(x^{*}, y^{*}\right), F\left(y^{*}, x^{*}\right)\right) \leq \frac{k}{2}\left(d\left(x^{*}, y^{*}\right)+d\left(y^{*}, x^{*}\right)\right)=k d\left(x^{*}, y^{*}\right) .
$$

Hence $d\left(x^{*}, y^{*}\right)$ and thus $x^{*}=y^{*}$.

Theorem 2.4 Under the conditions of Theorem 2.1, if we suppose that for each $(x, y) \in(X \times$ $X)^{F}$, there exists $z \in X$ such that $(x, z) \in E(G)$ and $(y, z) \in E(G)$, then if $\left(x^{*}, y^{*}\right) \in \operatorname{CFix}(F)$ we have $x^{*}=y^{*}$.

Proof Let $\left(x^{*}, y^{*}\right) \in \mathrm{CFix}(F)$. According to Theorem 2.1, we have that $\left(x^{*}, y^{*}\right) \in(X \times X)^{F}$. Hence, there exists $z \in X$ such that $\left(x^{*}, z\right) \in E(G)$ and $\left(y^{*}, z\right) \in E(G)$.

Now let $\left(x^{*}, z\right) \in E(G)$ and $\left(y^{*}, y^{*}\right) \in E\left(G^{-1}\right)$. Using Proposition 2.1(i) we shall have $\left(F^{n}\left(x^{*}, y^{*}\right), F^{n}\left(z, y^{*}\right)\right) \in E(G)$ and $\left(F^{n}\left(y^{*}, x^{*}\right), F^{n}\left(y^{*}, z\right)\right) \in E\left(G^{-1}\right)$.

If $\left(x^{*}, z\right) \in E(G)$ then $\left(z, x^{*}\right) \in E\left(G^{-1}\right)$ and using the same property we shall have $\left(F^{n}\left(x^{*}, z\right), F^{n}\left(z, x^{*}\right)\right) \in E(G)$ and $\left(F^{n}\left(z, x^{*}\right), F^{n}\left(x^{*}, z\right)\right) \in E\left(G^{-1}\right)$.

Finally if $\left(x^{*}, x^{*}\right) \in E(G)$ and $\left(z, y^{*}\right) \in E\left(G^{-1}\right)$ then $\left(F^{n}\left(x^{*}, z\right), F^{n}\left(x^{*}, y^{*}\right)\right) \in E(G)$ and $\left(F^{n}\left(z, x^{*}\right), F^{n}\left(y^{*}, x^{*}\right)\right) \in E\left(G^{-1}\right)$,

$$
\begin{aligned}
d\left(x^{*}, y^{*}\right)= & d\left(F^{n+1}\left(x^{*}, y^{*}\right), F^{n+1}\left(y^{*}, x^{*}\right)\right) \\
\leq & d\left(F^{n+1}\left(x^{*}, y^{*}\right), F^{n+1}\left(z, x^{*}\right)\right)+d\left(F^{n+1}\left(x^{*}, z\right), F^{n+1}\left(z, x^{*}\right)\right) \\
& +d\left(F^{n+1}\left(z, x^{*}\right), F^{n+1}\left(y^{*}, x^{*}\right)\right) .
\end{aligned}
$$

Using Lemma 2.2, we shall obtain

$$
\begin{aligned}
d\left(F^{n+1}\left(x^{*}, y^{*}\right), F^{n+1}\left(x^{*}, z\right)\right) & =d\left(F\left(F^{n}\left(x^{*}, y^{*}\right), F^{n}\left(y^{*}, x^{*}\right)\right), F\left(F^{n}\left(x^{*}, z\right), F^{n}\left(z, x^{*}\right)\right)\right) \\
& =d\left(F\left(F^{n}\left(x^{*}, z\right), F^{n}\left(z, x^{*}\right)\right), F\left(F^{n}\left(x^{*}, y^{*}\right), F^{n}\left(y^{*}, x^{*}\right)\right)\right) \\
& \leq \frac{k}{2}\left[d\left(F^{n}\left(x^{*}, z\right), F^{n}\left(x^{*}, y^{*}\right)\right)+d\left(F^{n}\left(z, x^{*}\right), F^{n}\left(y^{*}, x^{*}\right)\right)\right] \\
& \leq \frac{k^{n+1}}{2} d\left(y^{*}, z\right),
\end{aligned}
$$




$$
\begin{aligned}
d\left(F^{n+1}\left(x^{*}, z\right), F^{n+1}\left(z, x^{*}\right)\right) & =d\left(F\left(F^{n}\left(x^{*}, z\right), F^{n}\left(z, x^{*}\right)\right), F\left(F^{n}\left(z, x^{*}\right), F^{n}\left(x^{*}, z\right)\right)\right) \\
& \leq \frac{k}{2}\left[d\left(F^{n}\left(x^{*}, z\right), F^{n}\left(z, x^{*}\right)\right)+d\left(F^{n}\left(z, x^{*}\right), F^{n}\left(x^{*}, z\right)\right)\right] \\
& \leq k^{n+1} d\left(x^{*}, z\right), \\
d\left(F^{n+1}\left(z, x^{*}\right), F^{n+1}\left(y^{*}, x^{*}\right)\right) & =d\left(F\left(F^{n}\left(z, x^{*}\right), F^{n}\left(x^{*}, z\right)\right), F\left(F^{n}\left(y^{*}, x^{*}\right), F^{n}\left(x^{*}, y^{*}\right)\right)\right) \\
& =d\left(F\left(F^{n}\left(y^{*}, x^{*}\right), F^{n}\left(x^{*}, y^{*}\right)\right), F\left(F^{n}\left(z, x^{*}\right), F^{n}\left(x^{*}, z\right)\right)\right) \\
& \leq \frac{k}{2}\left[d\left(F^{n}\left(y^{*}, x^{*}\right), F^{n}\left(z, x^{*}\right)\right)+d\left(F^{n}\left(x^{*}, y^{*}\right), F^{n}\left(x^{*}, z\right)\right)\right] \\
& \leq \frac{k^{n+1}}{2} d\left(y^{*}, z\right) .
\end{aligned}
$$

Hence, we have

$$
d\left(x^{*}, y^{*}\right) \leq k^{n+1}\left(d\left(x^{*}, z\right)+d\left(y^{*}, z\right)\right) \rightarrow 0, \quad \text { as } n \rightarrow \infty .
$$

Thus $x^{*}=y^{*}$.

Theorem 2.5 Under the conditions of Theorem 2.1, if we suppose that there exists $(x, y) \in$ $(X \times X)^{F}$, such that $(x, y) \in E(G)$ and the sequence $\left(F^{n}(x, y)\right)_{n \in \mathbb{N}}$ converges to $x^{*}(x)$ and $\left(F^{n}(y, x)\right)_{n \in \mathbb{N}}$ converges to $y^{*}(y)$, as $n \rightarrow \infty$, then $x^{*}=y^{*}$.

Proof Let $(x, y) \in(X \times X)^{F}$, such that $(x, y) \in E(G)$.

Hence $\left(F^{n}(x, y), F^{n}(y, x)\right) \in E(G)$ and $\left(F^{n}(y, x), F^{n}(x, y)\right) \in E\left(G^{-1}\right)$

$$
d\left(x^{*}, y^{*}\right) \leq d\left(x^{*}, F^{n+1}(x, y)\right)+d\left(F^{n+1}(x, y), F^{n+1}(y, x)\right)+d\left(F^{n+1}(y, x), y^{*}\right) .
$$

Using the property of G-contraction we shall have

$$
\begin{aligned}
d\left(F^{n+1}(x, y), F^{n+1}(y, x)\right) & \leq k d\left(F^{n}(x, y), F^{n}(y, x)\right) \\
& \leq k\left(d\left(x^{*}, F^{n}(x, y)\right)+d\left(x^{*}, y^{*}\right)+d\left(y^{*}, F^{n}(y, x)\right)\right) .
\end{aligned}
$$

Hence

$$
\begin{aligned}
d\left(x^{*}, y^{*}\right) \leq & d\left(x^{*}, F^{n+1}(x, y)\right)+k\left(d\left(x^{*}, F^{n}(x, y)\right)+d\left(x^{*}, y^{*}\right)\right. \\
& \left.+d\left(y^{*}, F^{n}(y, x)\right)\right)+d\left(F^{n+1}(y, x), y^{*}\right), \\
d\left(x^{*}, y^{*}\right) \leq & \frac{1}{1-k} d\left(x^{*}, F^{n+1}(x, y)\right)+k d\left(x^{*}, F^{n}(x, y)\right) \\
& +d\left(F^{n+1}(y, x), y^{*}\right)+k d\left(y^{*}, F^{n}(y, x)\right) .
\end{aligned}
$$

Hence if $n \rightarrow \infty$, then $d\left(x^{*}, y^{*}\right)=0$, and thus $x^{*}=y^{*}$.

Remark 2.2 Let $(X, d)$ be a partially ordered set and $d$ be a metric on $X$ such that $(X, d)$ is a complete metric space. Let $E(G)=\{(x, y) \in X \times X: x \leq y\}$. In this case we obtain all the results from [1]. 
Remark 2.3 It is obvious that if we consider a function $f: X \rightarrow X, f(x)=F(x, x)$ all these results concerning the coupled fixed point of the mapping $F$ result in the existence and uniqueness results for the fixed point of $f$.

\section{Applications}

Let us consider the following integral systems:

$$
\left\{\begin{array}{l}
x(t)=\int_{a}^{b} f(t, s, x(s), y(s)) d s+g(t), \\
y(t)=\int_{a}^{b} f(t, s, y(s), x(s)) d s+g(t),
\end{array} \quad t \in[a, b],\right.
$$

and

$$
\left\{\begin{array}{l}
x(t)=\int_{a}^{t} f(t, s, x(s), y(s)) d s+g(t), \\
y(t)=\int_{a}^{t} f(t, s, y(s), x(s)) d s+g(t),
\end{array} \quad t \in[a, b] .\right.
$$

The purpose of this section is to give existence and uniqueness results for the solution of the systems (3.1) and (3.2) using Theorem 2.1.

We shall discuss first the system (3.1).

Let us consider $X:=C\left([a, b], \mathbb{R}^{n}\right)$ with the usual supremum norm, i.e. $\|x\|=$ $\max _{t \in[a, b]}|x(t)|$, for $x \in C\left([a, b], \mathbb{R}^{n}\right)$.

Consider also the graph $G$ defined by the partial order relation, i.e.

$$
x, y \in X, \quad x \leq y \quad \Leftrightarrow \quad x(t) \leq y(t), \quad \text { for any } t \in[a, b] .
$$

Hence $(X,\|\cdot\|)$ is a complete metric space endowed with a directed graph $G$.

If we consider $E(G)=\{(x, y) \in X \times X: x \leq y\}$, then the diagonal $\Delta$ of $X \times X$ is included in $E(G)$. On the other hand $E\left(G^{-1}\right)=\{(x, y) \in X \times X: y \leq x\}$.

Moreover, $(X,\|\cdot\|, G)$ has the properties $\left(A_{1}\right)$ and $\left(A_{2}\right)$.

In this case $(X \times X)^{F}=\{(x, y) \in X \times X: x \leq F(x, y)$ and $F(y, x) \leq y\}$.

Theorem 3.1 Consider the system (3.1). Suppose

(i) $f:[a, b] \times[a, b] \times \mathbb{R}^{n} \times \mathbb{R}^{n} \rightarrow \mathbb{R}^{n}$ and $g:[a, b] \rightarrow \mathbb{R}^{n}$ are continuous;

(ii) for all $x, y, u, v \in \mathbb{R}^{n}$ with $x \leq u, v \leq y$ we have $f(t, s, x, y) \leq f(t, s, u, v)$, for all $t, s \in[a, b]$

(iii) there exists $0 \leq k<1$ such that

$$
\begin{gathered}
|f(t, s, x, y)-f(t, s, u, v)| \leq \frac{k}{2(b-a)}(|x-u|+|y-v|), \\
\text { for each } t, s \in[a, b], x, y, u, v \in \mathbb{R}^{n}, x \leq u, v \leq y ;
\end{gathered}
$$

(iv) there exists $\left(x_{0}, y_{0}\right) \in X \times X$ such that

$$
\begin{aligned}
& x_{0}(t) \leq \int_{a}^{b} f\left(t, s, x_{0}(s), y_{0}(s)\right) d s+g(t), \\
& y_{0}(t) \geq \int_{a}^{b} f\left(t, s, y_{0}(s), x_{0}(s)\right) d s+g(t),
\end{aligned}
$$

Then there exists at least one solution of the integral system (3.1). 
Proof Let $F: X \times X \rightarrow X,(x, y) \longmapsto F(x, y)$, where

$$
F(x, y)(t)=\int_{a}^{b} f(t, s, x(s), y(s)) d s+g(t), \quad t \in[a, b] .
$$

In this way, the system (3.1) can be written as

$$
\left\{\begin{array}{l}
x=F(x, y) \\
y=F(y, x)
\end{array}\right.
$$

It can be seen, from (3.4), that a solution of this system is a coupled fixed point of the mapping $F$.

We shall verify if the conditions of Theorem 2.1 are fulfilled.

Let $x, y, u, v \in X$ such that $x \leq u$ and $v \leq y$. We have

$$
\begin{aligned}
F(x, y)(t) & =\int_{a}^{b} f(t, s, x(s), y(s)) d s+g(t) \\
& \leq \int_{a}^{b} f(t, s, u(s), v(s)) d s+g(t)=F(u, v)(t), \quad \text { for each } t \in[a, b] \\
F(v, u)(t) & =\int_{a}^{b} f(t, s, v(s), u(s)) d s+g(t) \\
& \leq \int_{a}^{b} f(t, s, y(s), x(s)) d s+g(t)=F(y, x)(t), \quad \text { for each } t \in[a, b]
\end{aligned}
$$

Hence, if $x \leq u$ and $v \leq y$, then $F(x, y) \leq F(u, v)$ and $F(v, u) \leq F(y, x)$, which, according to the definition of $E(G)$, shows that $F$ is edge preserving.

On the other hand

$$
\begin{aligned}
|F(x, y)(t)-F(u, v)(t)| & \leq \int_{a}^{b}|f(t, s, x(s), y(s))-f(t, s, u(s), v(s))| d s \\
& \leq \frac{k}{2(b-a)} \int_{a}^{b}(|x(s)-u(s)|+|y(s)-v(s)|) d s \\
& \leq \frac{k}{2}(\|x-u\|+\|y-v\|), \quad \text { for each } t \in[a, b] .
\end{aligned}
$$

Hence, there exists $k \in[0,1)$ such that

$$
\|F(x, y)-F(u, v)\| \leq \frac{k}{2}(\|x-u\|+\|y-v\|), \quad x \leq u, v \leq y
$$

Thus we see that $F$ is a $G$-contraction.

Condition (iv) from Theorem 3.1 shows that there exists $\left(x_{0}, y_{0}\right) \in X \times X$ such that $x_{0} \leq$ $F\left(x_{0}, y_{0}\right)$ and $F\left(y_{0}, x_{0}\right) \leq y_{0}$, which implies that $(X \times X)^{F} \neq \varnothing$.

On the other hand, because of (i) and of the fact that $(X,\|\cdot\|, G)$ has the properties $\left(A_{1}\right)$ and $\left(A_{2}\right)$ we find that either (i) or (ii) from Theorem 2.1 is fulfilled.

In this way, we see that $F: X \times X \rightarrow X$, defined by (3.3), verifies the conditions of Theorem 2.1 . 
Thus, there exists $\left(x^{*}, y^{*}\right) \in X \times X$, a coupled fixed point of the mapping $F$, which also is a solution of (3.1).

Let us consider now the system (3.2) and let us endow $X:=C\left([a, b], \mathbb{R}^{n}\right)$ with a Bielecki type norm, i.e. $\|x\|_{B}=\max _{t \in[a, b]}\left(|x(t)| e^{-\tau(t-a)}\right)$, for $x \in C\left([a, b], \mathbb{R}^{n}\right)$, where $\tau>0$ is arbitrarily chosen.

Consider, as previously, the graph $G$ defined by the partial order relation, i.e.

$$
x, y \in X, \quad x \leq y \quad \Leftrightarrow \quad x(t) \leq y(t), \quad \text { for any } t \in[a, b] .
$$

Hence $\left(X,\|\cdot\|_{B}\right)$ is a complete metric space endowed with a directed graph $G$.

If we consider $E(G)=\{(x, y) \in X \times X: x \leq y\}$, then the diagonal $\Delta$ of $X \times X$ is included in $E(G)$. On the other hand $E\left(G^{-1}\right)=\{(x, y) \in X \times X: y \leq x\}$.

Moreover, $\left(X,\|\cdot\|_{B}, G\right)$ has the properties $\left(A_{1}\right)$ and $\left(A_{2}\right)$.

In this case $(X \times X)^{F}=\{(x, y) \in X \times X: x \leq F(x, y)$ and $F(y, x) \leq y\}$.

Theorem 3.2 Consider the system (3.2). Suppose

(i) $f:[a, b] \times[a, b] \times \mathbb{R}^{n} \times \mathbb{R}^{n} \rightarrow \mathbb{R}^{n}$ and $g:[a, b] \rightarrow \mathbb{R}^{n}$ are continuous;

(ii) for all $x, y, u, v \in \mathbb{R}^{n}$ with $x \leq u, v \leq y$ we have $f(t, s, x, y) \leq f(t, s, u, v)$, for all $t, s \in[a, b]$

(iii) there exists $k \in[0,1)$ such that

$$
\begin{aligned}
& |f(t, s, x, y)-f(t, s, u, v)| \leq \frac{k}{2}(|x-u|+|y-v|), \\
& \quad \text { for each } t, s \in[a, b], x, y, u, v \in \mathbb{R}^{n}, x \leq u, v \leq y
\end{aligned}
$$

(iv) there exists $\left(x_{0}, y_{0}\right) \in X \times X$ such that

$$
\begin{aligned}
& x_{0}(t) \leq \int_{a}^{t} f\left(t, s, x_{0}(s), y_{0}(s)\right) d s+g(t), \\
& y_{0}(t) \geq \int_{a}^{t} f\left(t, s, y_{0}(s), x_{0}(s)\right) d s+g(t),
\end{aligned}
$$

Then there exists at least one solution of the integral system (3.2).

Proof Let $F: X \times X \rightarrow X,(x, y) \longmapsto F(x, y)$, where

$$
F(x, y)(t)=\int_{a}^{t} f(t, s, x(s), y(s)) d s+g(t), \quad t \in[a, b]
$$

In this way, the system (3.2) can be written as

$$
\left\{\begin{array}{l}
x=F(x, y), \\
y=F(y, x) .
\end{array}\right.
$$

As previously, from (3.6), the solution of this system is a coupled fixed point of the mapping $F$. 
Let $x, y, u, v \in X$ such that $x \leq u$ and $v \leq y$,

$$
\begin{aligned}
F(x, y)(t) & =\int_{a}^{t} f(t, s, x(s), y(s)) d s+g(t) \\
& \leq \int_{a}^{t} f(t, s, u(s), v(s)) d s+g(t)=F(u, v)(t), \quad \text { for each } t \in[a, b] ; \\
F(v, u)(t) & =\int_{a}^{t} f(t, s, v(s), u(s)) d s+g(t) \\
& \leq \int_{a}^{t} f(t, s, y(s), x(s)) d s+g(t)=F(y, x)(t), \quad \text { for each } t \in[a, b] .
\end{aligned}
$$

Hence, if $x \leq u$ and $v \leq y$, then $F(x, y) \leq F(u, v)$ and $F(v, u) \leq F(y, x)$, which, according to the definition of $E(G)$, shows that $F$ is edge preserving.

On the other hand

$$
\begin{aligned}
|F(x, y)(t)-F(u, v)(t)| & \leq \int_{a}^{t}|f(t, s, x(s), y(s))-f(t, s, u(s), v(s))| d s \\
& \leq \frac{k}{2} \int_{a}^{t}(|x(s)-u(s)|+|y(s)-v(s)|) e^{-\tau(s-a)} e^{\tau(s-a)} d s \\
& \leq \frac{k}{2 \tau}\left(\|x-u\|_{B}+\|y-v\|_{B}\right) e^{\tau(t-a)}, \quad \text { for each } t \in[a, b] .
\end{aligned}
$$

Multiplying the above relation with $e^{-\tau(t-a)}$ and choosing $\tau \geq 1$, we find that there exists $k \in[0,1)$ such that

$$
\|F(x, y)-F(u, v)\|_{B} \leq \frac{k}{2}\left(\|x-u\|_{B}+\|y-v\|_{B}\right), \quad x \leq u, y \leq v .
$$

Hence we see that $F$ is a $G$-contraction.

Condition (iv) from Theorem 3.1, shows that there exists $\left(x_{0}, y_{0}\right) \in X \times X$ such that $x_{0} \leq$ $F\left(x_{0}, y_{0}\right)$ and $F\left(y_{0}, x_{0}\right) \leq y_{0}$, which implies that $(X \times X)^{F} \neq \varnothing$.

On the other hand, because of (i) and of the fact that $\left(X,\|\cdot\|_{B}, G\right)$ has the properties $\left(A_{1}\right)$ and $\left(A_{2}\right)$ we see that either (i) or (ii) from Theorem 2.1 is fulfilled.

In this way, we see that $F: X \times X \rightarrow X$, defined by (3.5), verifies the conditions of Theorem 2.1.

Thus, there exists $\left(x^{*}, y^{*}\right) \in X \times X$, a coupled fixed point of the mapping $F$, which also is a solution of (3.2).

In what follows we shall suppose that the conditions of Theorems 3.1 and 3.2 are satisfied.

Remark 3.1 In both cases we are working with $E(G)=\{(x, y) \in X \times X: x \leq y\}$. Equation (2.2) becomes the following.

For every $\left(x_{1}, y_{1}\right),\left(x_{2}, y_{2}\right) \in X \times X$ there exists $\left(z_{1}, z_{2}\right) \in X \times X$ such that

$$
\begin{aligned}
& x_{1} \leq z_{1}, \quad z_{2} \leq y_{1}, \\
& x_{2} \leq z_{1}, \quad z_{2} \leq y_{2} .
\end{aligned}
$$


It is obvious that we can find such a pair $\left(z_{1}, z_{2}\right) \in X \times X$ simply considering

$$
\begin{aligned}
& z_{1}=\max \left\{x_{1}, x_{2}\right\}, \\
& z_{2}=\min \left\{y_{1}, y_{2}\right\} .
\end{aligned}
$$

In this respect, if the conditions of Theorems 3.1 and 3.2 are fulfilled, (3.7) implies the uniqueness for the solution of both systems.

Remark 3.2 If $\left(x^{*}, y^{*}\right) \in \mathrm{CFix}(F)$ with $x^{*} \leq y^{*}$, then $x^{*}=y^{*}$.

Remark 3.3 If we suppose that for each $(x, y) \in(X \times X)^{F}$, there exists $z \in X$ such that $x \leq z$ and $y \leq z$, then if $\left(x^{*}, y^{*}\right) \in \operatorname{CFix}(F)$ we have $x^{*}=y^{*}$.

Remark 3.4 If we suppose that there exists $(x, y) \in(X \times X)^{F}$, such that $x \leq y$ and the sequence $\left(F^{n}(x, y)\right)_{n \in \mathbb{N}}$ converges to $x^{*}(x)$ and $\left(F^{n}(y, x)\right)_{n \in \mathbb{N}}$ converges to $y^{*}(y)$, as $n \rightarrow \infty$, then $x^{*}=y^{*}$.

\section{Competing interests}

The authors declare that they have no competing interests.

\section{Authors' contributions}

All authors contributed equally to the writing of this paper. All authors read and approved the final manuscript.

Received: 6 April 2014 Accepted: 13 June 2014 Published: 22 Jul 2014

\section{References}

1. Gnana Bhaskar, T, Lakshmikantham, V: Fixed point theorems in partially ordered metric spaces and applications. Nonlinear Anal. 65, 1379-1393 (2006)

2. Jachymski, J: The contraction principle for mappings on a metric space with a graph. Proc. Am. Math. Soc. 136, 1359-1373 (2008)

3. Gwóźdź-Lukawska, G, Jachymski, J: IFS on a metric space with a graph structure and extensions of the Kelisky-Rivlin theorem. J. Math. Anal. Appl. 356, 453-463 (2009)

4. Beg, I, Butt, AR, Radojevic, S: The contraction principle for set valued mappings on a metric space with a graph. Comput. Math. Appl. 60, 1214-1219 (2010)

5. Chifu, IC, Petrusel, GR: Generalized contractions in metric spaces endowed with a graph. Fixed Point Theory Appl. 2012, 161 (2012)

6. Harjani, J, Sadarangani, K: Fixed point theorems for weakly contractive mappings in partially ordered sets. Nonlinear Anal. 71, 3403-3410 (2009)

7. Nieto, JJ, Rodríguez-López, R: Contractive mapping theorems in partially ordered sets and applications to ordinary differential equations. Order 22, 223-239 (2005)

8. Nieto, JJ, Rodríguez-López, R: Existence and uniqueness of fixed points in partially ordered sets and applications to ordinary differential equations. Acta Math. Sin. Engl. Ser. 23, 2205-2212 (2007)

9. Nieto, JJ, Pouso, RL, Rodríguez-López, R: Fixed point theorems in ordered abstract spaces. Proc. Am. Math. Soc. 135, 2505-2517 (2007)

10. O'Regan, D, Petrușel, A: Fixed point theorems in ordered metric spaces. J. Math. Anal. Appl. 341, 1241-1252 (2008)

11. Ran, ACM, Reurings, MC: A fixed point theorem in partially ordered sets and some applications to matrix equations. Proc. Am. Math. Soc. 132, 1435-1443 (2004)

12. Chifu, IC, Petrusel, GR: Coupled fixed point theorems in metric spaces endowed with a graph (submitted) 